\title{
A relação saber-poder na organização e repre-sentaçao do conhecimento
}

\author{
La relación saber-poder en la representación y organización del conocimiento
}

The relationship between power and knowledge in knowledge representation and organization

\section{Solange Puntel Mostafa y Deise SABbag}

Departamento de Educação, Informação e Comunicação. Faculdade de Filosofia, Ciências e Letras de Ribeirão Preto. Universidade de São Paulo - Av. Bandeirantes, 3900 - Ribeirão Preto - SP - BRASIL. smostafa@ffclrp.usp.br; deisesabbag@usp.br

\section{Resumen}

Se aborda la trayectoria del investigador y profesor Eduardo Ismael Murguia a través de sus trabajos orientados a las relaciones entre el saber y el poder en la organización y representación del conocimiento. Se consideran, principalmente, los últimos cinco años de su producción, período en el cual su preferencia por los ensamblajes mecánicos como unidad de análisis quedó más evidente. Se presenta su fase materialista a partir de la exposición "Para que guardar" de la cual fue curador y donde la problematización de los temas del coleccionismo se revistió de aspectos filosóficos. Se considera que a partir de esa exposición el autor inicia nuevas determinaciones teóricas para hablar sobre los objetos y sobre las instituciones, culminando en su trabajo postdoctoral "Da Ciência da Informação à Cultura Material" ("De la Ciencia de la Información a la Cultura Material"). Se presenta la influencia que el autor absorbió de las lecturas de las obras de Foucault y Deleuze, las cuales culminaron en una nueva forma de pensar la documentación en Brasil a partir de la teorización de la relación entre poder y saber: los dos conceptos filosóficos de acontecimiento y de agenciamiento; de los saberes legítimos y saberes sujetados; de la arqueología y de la genealogía. Se concluye mostrando que los textos del autor sobre saber-poder apuntan a una inadecuación de criterios cientificistas y hegemónicos de la Ciencia de la Información en su formación discursiva, resaltando que la recomendación de Eduardo Ismael Murguia es que utilicemos los procesos arqueológicos y genealógicos en el análisis de nuestra ciencia.

Palabras clave: Ciencia de la información. Organización del conocimiento. Murguía Marañón, Eduardo Ismael. Teoría del Saber-Poder. Epistemología. Colecciones. Coleccionismo.

\section{Um novo arquivista na Ciência da Informação}

Um novo arquivista foi nomeado na cidade. É assim que Deleuze inicia sua homenagem a Foucault em livro homônimo e é com essa crença que nos aproximamos dos trabalhos de Murguia, voltados às relações entre o saber e o poder na organização e representação do conhecimento. São trabalhos de um novo arquivista na Ciência

\section{Abstract}

This paper addresses aspects of researcher and professor Eduardo Ismael Murguia's trajectory, through his works dedicated to the relationships between knowledge and power in knowledge organization and representation. It mainly covers the last five years of his work, a period in which his preference for machinic agencements as a unit of analysis becomes more evident. It presents his materialistic phase based on the exhibition "Para que guardar?" ("Why keep/collect [things]?"), which Murguia curated and in which the problematization of the themes of collecting took on philosophical aspects. It considers that, from that exhibition on, Murguia begins new theoretical determinations to talk about objects and institutions, culminating in his post-doctoral work "Da Ciência da Informação à Cultura Material" ("From Information Science to Material Culture"). It presents the influence that Murguia absorbed by reading the works of Foucault and Deleuze, which culminated in a new way of thinking documentation in Brazil, based on the theorization between power and knowledge: the two philosophical concepts of event and agencement; of legitimate knowledge and subjected knowledge; of archeology and genealogy. The conclusion shows that Murguia's texts about knowledge-power point to an inadequacy of scientistic and hegemonic criteria of Information Science in its discursive formation, stressing that Eduardo Ismael Murguia's recommendation is that we should use the archeologic and genealogic processes in the analysis of our science.

Keywords: Information Science. Knowledge Organization. Murguía Marañón, Ismael Eduardo. KnowlegePower Theory. Epistemology. Colections. Coleccionismo.

da Informação. Um arquivista que, tal como Foucault, desliza na superfície dos acontecimentos com humor e leveza, só possíveis para quem visita as profundezas do saber como um dom. Eduardo Murguia possui a potência de criação de pensamento novo. Nunca foi afeito a revisões bibliográficas pois sempre se dirigiu aos textos com problematizações próprias e perguntas originais. Quando Murguia comenta a dupla identidade de Michel Foucault em ser a um só tempo, filósofo e 
historiador, é bem possível que esteja falando de si mesmo. Pois o seu legado é o de um intelectual que não dispensou nem a história, nem a filosofia, sendo também possível que filósofos cobrem dele a tradição da escrita filosófica tanto quanto os historiadores lhe peçam disciplinas mais simbólicas para compor o seu arquivo. Murguia nunca se curvou ao simbólico ou à linguagem, preferindo sempre os agenciamentos maquínicos como unidade de análise. Preferência que foi ficando mais clara nos últimos cinco anos da sua produção.

Tomamos como marco inicial da sua fase 'materialista' a exposição em que foi curador chamada "Para que Guardar?" na qual pretendeu evidenciar a cultura material por meio de coleções de objetos. Lemos na ementa da exposição:

Alguns [objetos] inusitados, outros banais, mas que adquirem um valor de peças únicas quando colecionadas. Moedas, relógios de bolso, cartões telefônicos, cartões postais, maços de cigarro, cédulas, bolachas de chope, pinguins, porquinhos, corujas e carrinhos Hot Weels, são alguns dos objetos encontrados na exposição.

Murguia não escondia sua preocupação na montagem da exposição com a chegada dos pinguins e outros objetos que pudessem infantilizar a exposição uma vez que ela foi composta pelas coleções particulares e privadas dos cidadãos do município e região. Mas tudo reunido, aquela exposição atraiu crianças e adultos, fazendo todos refletirem sobre colecionismo como algo sério e permanente na história dos homens. É que a forma de problematizar os temas do colecionismo revestiu-se de aspectos filosóficos de tal maneira que os objetos não eram simples objetos em exposição, mas parte de uma estética da existência de cada colecionador, e por extensão, de cada um de nós. Os orgulhosos colegas da Universidade de São Paulo (USP) sentiam-se um pouco como co-curadores, apesar de sabermos que tal exposição era fruto de um devir-artista daquele novo arquivista nomeado na cidade.

O ano desta exposição era 2010 e tínhamos na cidade um arquivista atento às forças do fora. Uma exposição nascida das aulas sobre "Desenvolvimento de Coleções" num Curso de Graduação em Biblioteconomia na Universidade de São Paulo da cidade de Ribeirão Preto. Quando todos pensávamos que a disciplina era voltada às coleções bibliográficas e às bibliotecas, o novo arquivista fez-nos ver que coleções e colecionismo era algo que ia além dos livros e de nossas bibliotecas. Os livros, aliás, bem como as bibliotecas receberiam de Murguia (2014, p. 168) outras teorizações distintas daquelas praticadas pela biblioteconomia
[...] eu considero o livro como algo mais de que informação. A proposta do livro como semióforo de Pomian é mais assertivo. O fim último do livro não é somente informar, ele também representa. E essa representação não indica unicamente o prestígio, a cultura, o refinamento ou a riqueza de seu possuidor. Enquanto discurso, o livro significa a possibilidade de ser ele e não outro, de se relacionar com uns e de excluir outros.

E a associação realizada por Murguia entre o livro e a biblioteca:

Se o livro é um discurso, a biblioteca também o é, seja pela sua disposição preestabelecida por algum código de classificação, ou seja, pelas perguntas que ocasiona sua distribuição espacial, como no caso de Warburg (Murguia, 2014, p. 169).

As bibliotecas passam a ser vistas, desde a perspectiva do colecionismo em texto de 2013 em que os livros são percebidos como objetos especiais com história própria e selecionados por afetos, segundo os encontros de cada colecionador (Pedrão y Murguia, 2013).

Foi a partir da exposição 'Para que guardar' que o seu 'materialismo' explodiu em novas determinações teóricas que pudessem falar algo sobre os objetos ou sobre as instituições. Daí o título que deu ao seu projeto de pós-doutorado: $\mathrm{Da} C i$ ência da Informação à Cultura Material: os conceitos de Fundo e Coleção como princípios da organização (Murguia, 2010a).

Murguia $(2014$, p. 168) estará sempre atento à seriação ou à construção das séries de elementos de um conjunto, por isso ao comentar sobre a contribuição de Buckland lhe parece importante alinhavar os elementos de uma série:

[....] os trabalhos que conheço sobre documento, escapam à questão da sua seriação, conceito amplamente desenvolvido pela arquivologia. Ou seja, ao fato de que o documento quando isolado é objeto de museu, mas enquanto a seu agir, ele sempre o faz pela relação que tem com outros documentos.

A necessidade da seriação vem não apenas dos estudos arquivísticos mas de sua experiência como historiador leitor de Foucault, já que o método serial seria, também, uma invenção foucauItiana na nova maneira de distribuir os fatos no tempo (Murguia, 2014 p. 169):

[....] os estudos da informação como coisa, se restringem a uma reflexão de um único documento, nesse sentido falta ver os agenciamentos desse documento dentro de uma série ou de uma coleção. E também as articulações dessas séries, dessas coleções, desses conjuntos, enquanto tais e a respeito de outros.

Ao pensar os objetos Murguia também volta-se para os documentos como objetos e é quando Michel Foucault comparece em suas publicações 
de maneira mais explícita. A Microfísica do Poder" aparece em texto de 2011 ao analisar "As percepções do documento na Historiografia, Documentação e Ciência da Informação, texto no qual esclarece que sua intenção é (Murguia, 2011 p. 42)

[...] enfatizar a construção da informação materializada em documentos institucionais e os estratos burocráticos que influenciam e determinam, por meio de relações e jogos de poder, a construção de documentos, de emergências e de definições sociais e culturais na esfera patrimonial.

Em nota de rodapé esclarece que toma de Foucault a expressão 'estratos burocráticos'.

Veremos a noção de documento como um agenciamento institucional (Grigoleto y Murguia, 2013) e pensamos mais uma vez que Michel Foucault vai caracterizar a materialidade do enunciado também através da instituição. Percebe-se nessas teorizações que o autor busca apoio nos textos neodocumentalistas, principalmente os assinados por Bernd Frohmann. Mas há de se notar a inspiração foucaultiana de Frohmann ao basear-se nos enunciados de Foucault, nos quais não importa tanto o significado ou a simbologia da linguagem, mas apenas o fato de que o discurso portar uma materialidade que permite ou proíbe sua realização. Foucault talvez entenda essa materialidade dos enunciados por uma inspiração espinosista, na qual a relação entre massa e energia da física moderna eisteiniana se traduza no poder de afetar e produzir efeitos. O que interessa a esta compreensão frohmanniana é que todo discurso tem um suporte histórico, institucional, uma materialidade que permite ou proíbe sua realização.

É com essa inspiração a um só tempo foucaultiana e deleuziana que Murguia quer estudar a documentação, em seus últimos escritos. Deleuze entra meio sorrateiro em sua teorização. É que o filósofo do virtual também inspira Frohmann desde a sua revisita ao Documento em 2009; mais tarde, ao criar o conceito filosófico de Documentalidade, Frohmann apresenta-o ligado a quatro propriedades, a saber: funcionalidade, contingência, complexidade e agência (ou agenciamento). Interessa-Ihe explorar a documentação e os documentos como agenciamentos heterogêneos ou ainda associações complexas, contingentes e, sobretudo heterogêneas (documentos podem ser papéis, mas há sempre pessoas, processos e coisas em volta dos papéis) e afinal, os papéis ou as ideias referem-se às coisas do mundo (Mostafa, 2011). O agenciamento é uma das propriedades do conceito de documentalidade; o agenciamento combina, acopla ou fa- brica elementos heterogêneos distribuindo efeitos, reposicionando formas e pensamentos. É essa materialidade que interessa a Murguia.

Frohmann explica no texto sobre a Documentalidade (Mostafa, 2011) que a partir do antílope de Suzane Briet há um mundo grávido de virtualidades: todo objeto é virtualmente um documento, mas a sua atualização depende de coordenadas espaço-temporais. Para Suzane Briet, documento é visto como prova de um fato pois ela trabalha com o atual. Para Briet, o documento é constituído quando é institucionalizado, por exemplo o objeto no museu. Frohmann chegou a mesma noção de documento mas para ele o documento porta uma força (virtus) que gera vários fatos; vê-se que ele supõe a existência do virtual. Frohmann, ao criar o conceito filosófico de Documentalidade fez um percurso inverso: ele foi do atual (Suzanne Briet) ao virtual. Isso porque todo conceito, toda a ideia é virtual, é força, é virtus. Mas o virtual e o atual estão intimamente conectados.

Os dois conceitos filosóficos Acontecimento e Agenciamento tão caros a Michel Foucault e a Gilles Deleuze e são agora operadores importantes para Murguia pensar a Documentação no Brasil, bem como o surgimento da Ciência da Informação em estado de ciência régia em relação às práticas biblioteconômicas e arquivísticas. $\mathrm{O}$ agenciamento remete ao modo concreto de produção de realidade, seja a realidade material ou imaterial, e não à uma verdade que representaria o real. Ou a uma saudade histórica capaz de indicar os feitos de Paul Otlet como a origem da Ciência da Informação anglo-saxônica. Murguia esforça-se por evitar anacronismos e por evitar idealizar as forças em jogo que constituem qualquer acontecimento "minha proposta aponta para a possibilidade de estudar a documentação na sua singularidade, no momento que se constitui como acontecimento, sem considerar o que veioa-ser" (Murguia, 2014, p. 179).

Refere-se 0 autor às atividades de documentação no Brasil realizadas pelo então Instituto Brasileiro de Bibliografia e Documentação (IBBD); "considero que foram suas práticas discursivas e/ou teóricas, e suas práticas institucionais que constituíram o campo da documentação como acontecimento histórico" (Murguia, 2014-2015, p. 178).

O leitor atento perceberá uma certa irritação de Murguia com o humanismo subjacente de Michel Buckland e quiçá essa seja uma hipótese geral que ele julga importante desenvolver; pois desconfia ser o neodocumentalismo um movimento que nega a cientificidade da Ciência da Informa- 
ção. É como se os neodocumentalistas contestassem o cientificismo da 'Ciência da Informação' ensejando um viés mais humanista e erudito, menos matemático ou talvez mais novecentista para esta ciência. Murguia se coloca contra esse movimento em afirmações como essas:

[....] estou tentado a admitir a emergência de uma busca nos neodocumentalistas, por uma ciência da informação mais humanista, menos tecnológica, motivo pelo qual se apela à documentação. Eu não estou defendendo uma ciência da informação unicamente quantitativa e tecnológica. Como toda ciência, ela é uma construção. Pessoalmente, acredito que ela deva ampliar seu objeto, seus métodos, suas abordagens para as áreas das humanas e sociais. O problema que vejo é que esse anseio não pode ser colocado na sua história, por que não estaríamos sendo verdadeiros (Murguia, 2014, p. 180).

Coisas do presente no passado é uma prática filosófica ou uma filosofia da história que Murguia esforça-se por evitar. A sua filosofia da história tem também uma inspiração arqueológica de Michel Foucault. São epistemes e não períodos históricos o que Michel Foucaut desenvolve em sua prática arqueológica. Trata-se de delinear as condições de possibilidade de um saber, de uma prática e de seus dizeres, entendendo o seu funcionamento e a sua pressuposição recíproca. As palavras e as coisas estão em pressuposição recíproca, apesar de suas formas próprias manterem-se irredutíveis e autônomas. Há sempre uma linha de fuga ou uma linha virtual atravessando a experiência real, pondo em variação permanente essas condições de possibilidade das palavras e das coisas, condicionando por assim dizer todo o processo de compreensão e produção da realidade.

Entendemos assim que há uma filosofia da história acontecimental praticada por Murguia baseada na noção foucaultiana de episteme; diferentemente de período histórico a noção de episteme delinea condições de possibilidade do saber, um saber sempre acontecimental, cuja linha de variação virtual determina os limites do que pode ser sentido, dito ou pensado. É com essa noção epistêmica da história que a arqueologia investiga as condições de emergência dos saberes. Há uma ordem e um modo de ser e pensar em cada episteme de tal maneira que não nos é dado ultrapassar essa ordem com as categorias do presente. $O$ desafio é não tomar o passado pelo presente $\mathrm{e}$ isto acontece sempre quando não tomamos distancia temporal entre agora e o que se passou, tanto quanto não tomar o presente pelo passado que, como por inércia ou evolução teria chegado aqui. Daí a importância que Murguia atribui às rupturas e às descontinuidades dos fatos históricos, tratando-os como acontecimentos históricos para não perder o seu acontecimento enquanto acontece; é isso que o autor quer dizer quando intenciona tratar a documentação em sua 'singularidade'.

A história da documentação deveria então ser contada com esta noção de 'corte' ou descontinuidade. Por outro lado, como explica Machado (2007 p. 140) a noção de descontinuidade da arqueologia não é a mesma que a de 'corte epistemológico' da epistemologia: "[a arqueologia] não diz respeito a uma ciência e menos ainda a um único conceito. É muito mais vasta: tem a extensão da própria episteme, atinge o conjunto dos saberes de determinada época".

Não the interessa uma historiografia como a praticada por Rayward (1996) onde as categorias de Braudel viriam dominar a análise dos fatos históricos de longa duração, e onde os acontecimentos seriam acomodados em processos de curta duração. Uma menção a Rayward elucida o que estamos falando (Murguia, 2014, p. 178):

[...] existe uma intencionalidade explícita em Rayward em fazer uma história da documentação, pelo "mérito" de ter sido antecedente da ciência da informação. Ainda, ele escolhe como caminho argumentativo, o viés do pioneirismo; e o caráter visionário de Otlet que se antecipando ao seu tempo coloca problemas que seriam resolvidos pelas novas tecnologias no âmbito da informação. Nesse sentido, ele propõe que as origens da ciência da informação, devam também ser procuradas em Otlet e suas propostas e visões institucionais e documentais.

Para Murguia, Otlet não poderia ver e dizer o que o seu tempo não Ihe permitia: "Pensar que o catálogo do IIB preanunciava a Internet é poético, ficcional, etc., mas não verdadeiro" (Murguia, 2014-2015, p. 179).

Murguia aposta em processos descontínuos para contar a história, donde a conclusão dos seus estudos de uma não continuidade entre a Documentação europeia e a Ciência da Informação americana ou anglo-saxônica (Murguia, 20142015, p. 181):

[...] considero que a documentação, seja no Brasil, na Europa ou nos Estados Unidos, deva ser analisada introduzindo a categoria histórica do acontecimento e a filosófica do ethos. Dessa forma, a pesquisa histórica pode levar a descobrir, que a documentação, assim como a ciência da informação são acontecimentos diferentes. Mas, ao mesmo tempo, podemos descobrir também o ethos comum e compartilhado da cientificidade em torno da qual foram construídas. 


\section{O saber-poder e a arqueologia}

Michel Foucault, no livro Microfísica do poder (2014, p. 4), concebe uma nova relação entre saber e poder. Isto porque segundo ele, a direita só colocava a questão do poder em termos jurídicos e, do lado do marxismo, o poder só seria pensado em termos de aparelho do Estado. Nos anos cinquenta, o cenário intelectual francês era dominado pelo marxismo e pela fenomenologia, de tal forma que um trabalho mais aberto sobre a concepção de poder só pôde nascer, segundo Foucault, "a partir de 1968, isto é, a partir das lutas cotidianas e realizadas na base com aqueles que tinham que se debater nas malhas mais finas da rede do poder". É neste livro que surgirão as novas explicações sobre o poder como uma relação de forças e a sua relação com a verdade, já que a própria verdade é poder. Bastante influenciado por Nietzsche, Foucault explica neste livro que "a verdade não existe fora do poder ou sem poder" e que "cada sociedade tem seu regime de verdade". Seguindo Nietzsche, para quem a verdade não existe senão como uma imposição de uma vontade de verdade, a relação entre discurso e verdade será um dos principais temas de Foucault no livro $A$ ordem do discurso e aí a vontade de verdade irá aparecer como um mecanismo de exclusão, pois "sabe-se que não se tem o direito de dizer tudo que não se pode falar de tudo em qualquer circunstância, que qualquer um enfim, não pode falar de qualquer coisa" (Foucault, 2015, p. 84).

A arqueologia é uma nova metodologia proposta pelo autor para o estudo das ciências humanas. Assim como Nietzsche, o trabalho de Foucault pode ser considerado uma crítica radical à metafísica ocidental. Nietzsche considera que a verdade não existe como instinto no homem; ao contrario, ela é historicamente produzida por relações de poder. Para a metafísica ocidental, de origem platônica e cristã, existe a verdade absoluta. Nietzsche rejeita tal concepção colocando a metafísica no mesmo lugar da ciência na mistificação da realidade. A ciência tanto quanto a metafísica possuem vontade de verdade e a questão de Nietzsche é se perguntar de onde vem essa vontade de verdade.

Como Foucault está nesta primeira fase de suas análises baseado na nova categoria do enunciado, ele dirá que cada sociedade possui os mecanismos que permitem distinguir os enunciados verdadeiros dos falsos. Assim, e esse é um ponto importante para as colocações que se seguem, um discurso acolhido como verdadeiro exclui outros, desqualificando-os, já que somente ele deve tornar-se hegemônico e com pretensões universais.
É a arqueologia que permite a Foucault analisar as ciências humanas enquanto saberes. A arqueologia é então o estudo das condições de existência dos discursos. Condições de existência não é o mesmo que condições de validade, uma vez que a arqueologia não está preocupada com a verdade, ou com os critérios de cientificidade próprios à epistemologia. $A$ arqueologia se distancia da epistemología na medida em que lida com saberes e não com conhecimento cientifico. A arqueologia aceita a verdade como uma configuração histórica a partir de um conjunto de regras daquilo que é permito dizer ou pensar em cada sociedade. A arqueologia funciona unicamente a partir de normas internas dos saberes de determinada época. E como o poder produz saber? O saber como materialidade, prática ou acontecimento é peça de um dispositivo político. Não há saber neutro; todo saber é político, ou seja, enredado em relações de poder. Saber e poder se implicam, mutuamente. Como esclarece Machado (2007 p. 177) "Todo ponto de exercício do poder, é ao mesmo tempo, um lugar de formação de saber".

\section{A hierarquia dos saberes}

Ao analisar a relação entre saber e poder na obra de Foucault, Deleuze (2006, p. 82) entende que as ciências humanas não podem ser separadas das relações de poder. São essas relações que as "tornam possíveis e que suscitam saberes mais ou menos capazes de atravessar um limiar epistemológico ou de formar um conhecimento". Mais adiante Deleuze constata que o poder, considerado abstratamente, não vê e não fala, é uma topeira; mas justamente faz ver e falar. De forma que "se as relações de poder implicam as relações de saber, estas, em compensação, supõem aquelas" (Deleuze, 2006, p. 89-90). Deste modo, ao fazer ver e ao fazer falar o poder produz verdades.

A verdade se identifica com a ciência e os "discursos científicos" cuja principal estratégia é desqualificar os saberes não-científicos, sujeitandoos. Ao discutir a pretensão cientificista do marxismo e da psicanálise Foucault (2010, p. 11) pergunta

Quais tipos de saber vocês querem desqualificar no momento em que vocês dizem ser esse saber uma ciência? Qual sujeito falante, qual sujeito discorrente, qual sujeito de experiência e de saber vocês querem minimizar quando dizem: eu, que faço esse discurso, faço um discurso científico e sou cientista?

Dirigindo-se aos presentes nesta aula de 1976 Foucault (2010, p. 11) responde: "Eu os vejo atribuindo aos que fazem esse discurso, efeitos de 
poder que o Ocidente, desde a Idade Média, atribuiu à ciência e reservou aos que fazem um discurso científico"

Ora, saberes desqualificados pelo discurso científico tornam-se saberes e discursos periféricos. São os conteúdos sujeitados "conteúdos históricos que foram sepultados, mascarados em coerências funcionais ou em sistematizações formais". Podem também ser considerados saberes sujeitados, "toda uma série de saberes que estavam desqualificados como saberes não conceituais, como saberes insuficientemente elaborados: saberes ingênuos, saberes hierarquicamente inferiores" (Foucault, 2010, p. 8). Nesse momento Foucault (2010, p. 11) cita Deleuze:

[...] a reativação dos saberes locais - "menores", talvez dissesse Deleuze - contra a hierarquização científica do conhecimento e seus efeitos de poder intrínsecos, esse é o projeto dessas genealogias.

A genealogia, segundo Foucault, é uma espécie de insurreição dos saberes sujeitados. A genealogia reativa os saberes locais e menores contra a hierarquização científica do conhecimento e seus efeitos de poder intrínsecos.

Baseado na teorização acima entre poder e saber, saberes legítimos e saberes sujeitados, arqueologia e genealogia, Murguia situa a Ciência da Informação como um saber-poder dominante frente a saberes contíguos de práticas informacionais. E pede atenção à pergunta de Foucault ao "se interrogar sobre a ambição de poder que a pretensão de ser ciência traz consigo". Murguia amplia a pergunta ao mesmo tempo que a redireciona para a Ciência a Informação a fim de perguntar "quais seriam os saberes que seriam desqualificados para se alcançar tal fim?" (Murguia, 2014-2015, p. 175). Com tranquilidade afirma que "no caso da ciência da informação, desde sua introdução no Brasil na década de 1970, ela se instaura como ciência, desqualificando outros saberes" (Murguia, 2014-2015, p. 175).

As práticas científicas permeiam tanto a Documentação quanto a Biblioteconomia ou Arquivologia. Mas Murguia se esforça para explicar que não compartilha com os neodocumentalistas a desconfiança sobre a cientificidade da Ciência da Informação. O que ele quer ressaltar é a predominância de uma área sobre as outras. Saberespoderes em disputa na organização e representação do conhecimento. Pela percepção do autor, a Ciência da Informação só adquiriu essa importância no mesmo movimento em que desqualificou os saberes tradicionais da Biblioteconomia, Documentação ou da Arquivologia (Murguia, 2014-2015, p.175):

[...] ninguém mais duvida que ela [a Ciência da Informação] não seja uma ciência, ela é uma ciência em todos os sentidos.... O que quero explicar é que existe uma dinâmica de poder pelo qual ele simplesmente se exerce e se exerce sobre nós, e que nossos trabalhos estão dentro desse processo. Por outro lado, também temos poder e desejamos exercelo. Ao ponto de querer, em alguns casos, impor nosso conceito de informação a esses saberes sujeitados, no caso, à arquivologia, à biblioteconomia e à museología.

E mais uma vez o autor analisa as relações de saber-poder na organização do conhecimento dizendo que todos os saberes são exercício de poder e em todos os saberes o poder é exercido. Assim, a biblioteconomia e a arquivologia, como saberes, exercem também o seu poder, tratandose de saberes-poderes. Mas o autor ressalta que, apesar de todos os saberes atuarem também como campos de poder, há disputa de poder também entre esses campos. E nesse sentido (Murguia, 2014, p. 6):

[...] consideramos que a ciência da informação também é um dispositivo de poder, se assumirmos seu estatuto de cientificidade perante as práticas e saberes tradicionais da biblioteconomia e da arquivologia.

Em outra oportunidade o autor fala abertamente sobre a 'discursividade' da Ciência da Informação e sua institucionalização na Biblioteconomia e Arquivologia (Murguia, 2010b); para tal análise toma "os enunciados discursivos da Ciência da Informação com o objetivo de comparar as maneiras pelas quais eles são apropriados, rejeitados e/ou ignorados por aquilo que chamaríamos duas variáveis: a Biblioteconomia e a Arquivologia.

Reconhece para esta análise as 'formações discursivas' da Ciência da Informação, mas sempre atento para as práticas não-discursivas ou para as 'condições materiais para seus agenciamentos'. O autor afirma que "todo agenciamento precisa de discursos. Discursos enunciados com o objetivo de validar dizeres e saberes sobre um objeto: a informação" (Murguia, 2010b, p. 5).

Ao se afastar da epistemologia para ser possível esboçar uma arqueologia dos enunciados da Ciência da Informação, o autor anuncia que vai tratar das relações de poder entre as três disciplinas, Ciência da Informação, Biblioteconomia e Arquivologia. Murguia atribui à Shera a percepção de que ciência da informação era nada mais que a biblioteconomia tradicional, mas acrescida de nova terminologia e novos métodos, dada a sua natureza interdisciplinar. Admite, no entanto, desenvolvimento próprio de algumas áreas, como por exemplo, a organização do conhecimento como uma das novidades da Ciência da Informação. Ao trazer algumas considerações de autores hoje clássicos na Ciência da Informação 
com Saracevic ou Borko, Murguia recupera Shannon e Weaver para evidenciar a transformação do enunciado Informação em Ciência da Informação. E conclui que essas transformações e apropriações nos conceitos configuram 'jogo político' para justificação acadêmica (Murguia, 2010 b, p. 12). Qual é então a novidade colocada por Murguia neste seu método comparativo entre as três disciplinas? A comparação mesma talvez se apresente como novidade: a Arquivologia também teve seu percurso de sistematização de suas práticas (manuais e princípios clássicos) durante os últimos cinquenta anos, até que "viuse obrigada a adaptar-se e redefinir-se norteada pela informação e sua ciência" (Murguia, 2010b, p. 19) inclusive delineando domínios comuns com a Ciência da Informação. Mas de maneira mais restritiva do que a Biblioteconomia. Murguia conclui que no caso da Arquivologia, a informação é um aspecto a mais, e na compreensão dos canadenses, é "uma espécie de estágio depois da administração e da história" (Idem).

Vê se por aqui a admiração de Murguia pelos processos documentais e por uma concepção da história renovada, o que talvez tenha justificado o questionamento ao canadense Terry Cook, em entrevista; Murguia insiste com o canadense sobre o papel da história na formação do arquivista, o valor da macro-avaliação nos processos arquivísticos e o significado da história arquivística. Tudo isso somado permitiu a Murguia compreender as três entidades contextuais inter-relacionadas mencionadas por Cook (2012, p. 150):

\footnotetext{
1) os criadores de documentos (ou seja, estruturas, agências, instituições, burocratas), 2) os processos sócio-históricos (isto é, funções, programas, atividades, transações - serviços- que o Estado oferece aos cidadãos, e que os cidadãos demandam do governo) e 3) os cidadãos, clientes, constituintes, ou grupos, os quais estas funções e estruturas afetam, e que por sua vez influenciam tanto a função como a estrutura, direta ou indiretamente, explícita ou implicitamente.
}

Estas três entidades contextuais são contempladas por Murguia em seus estudos sobre o documento como forma de poder e de materialização de valores patrimoniais.

Outra forma de analisar a relação saber-poder na Organização do Conhecimento $(\mathrm{OC})$ é apresentada pela área nomeada como Ética na Organização e Representação do Conhecimento.

$\mathrm{Na}$ literatura da área alguns autores apontam problemas éticos em relação à organização e representação do conhecimento, por exemplo nas questões que abordam a indexação, condensação de documentos, a classificação.
Hope Olson, em seu livro The power of name (2002), apresenta que o profissional tem a preferência pela escolha do conceito que será usado para representar um documento, a essa escolha a autora denominou poder de rotular ou nomear, já que os produtos documentários (e podemos considerar aqui como produtos documentários os catálogos com seus pontos de acesso por assunto) e os instrumentos de representação (como os sistemas de classificação e tesauros) não possuem neutralidade. Não possuem neutralidade porque são produtos e instrumentos construídos em um determinado momento histórico e espacial, refletindo os valores dominantes de uma sociedade.

Lembramos neste momento da citação de Durkheim, utilizada por Peter Burke (Durkheim apud Burke, 2003): "as categorias do pensamento humano nunca são fixadas de forma definitiva; elas se fazem, desfazem e refazem incessantemente: mudam com o lugar e com o tempo". Essa citação está no início do capítulo que trata sobre a classificação do conhecimento para ressaltar que a partir de Durkheim, os antropólogos começaram a levar a sério a classificação de outras pessoas por meio da investigação do contexto social. Ou seja, as classificações também se fazem, desfazem e refazem de acordo com o contexto histórico e social, incessantemente, e, dessa forma, não podemos considerá-las neutras, como preconiza Hope Olson, pois apresentam um critério e um conhecimento prévio que manifestam o desejo de uma determinada comunidade discursiva, ou nas palavras de Foucault, manifestam uma ordem ou vontades de verdades.

Retomamos aqui a relação entre discurso e verdade pois podemos considerar que, por não serem neutras, a organização e representação do conhecimento podem funcionar como um procedimento de exclusão a serviço da produção do discurso. Nas palavras de Foucault (2013, p. 8)

[...] suponho que em toda sociedade a produção do discurso é ao mesmo tempo controlada, selecionada, organizada e redistribuída por certo número de procedimentos que têm por função conjurar seus poderes e perigos, dominar seu acontecimento aleatório, esquivar sua pesada e temível materialidade.

Os sistemas de classificação do conhecimento, a indexação, a classificação, a catalogação, e tantos outros produtos, processos e instrumentos podem servir como procedimento de exclusão, e, como outros sistemas de exclusão, estão amparados por um suporte institucional, seja ela a biblioteca ou o arquivo. Os sistemas de exclusão, que tem por função a manutenção do poder por meio da produção do discurso, possuem como base e apoio o suporte institucional que "é ao 
mesmo tempo reforçada e reconduzida por toda uma espessura de práticas como a pedagogia, é claro, como o sistema de livros, da edição, das bibliotecas" (Foucault, 2013, p. 16-17). Este apoio institucional exerce sobre os outros discursos um certo tipo de pressão e coerção, e é aqui que o profissional deve estar atento quando, nas palavras de Olson, vai exercer o seu poder de nomear os discursos não dominantes encontrem também representação.

É neste sentido que a autora Hope Olson concentra suas pesquisas na análise crítica dos sistemas de classificação e representação de assuntos, tendo como temática de estudo o gênero feminino, o pós-estruturalismo e as perspectivas coloniais para examinar tendências existentes nas estruturas dos sistemas de organização do conhecimento.

Autores como Rafferty (2001) e Mai (2004) também realizam pesquisas na perspectiva de que os sistemas de classificação refletem uma realidade determinada, uma visão de mundo particular, uma visão particular do conhecimento, e que as escolhas dos assuntos que irão representar o conteúdo dos documentos são escolhas ideológicas que podem funcionar como procedimento de exclusão de minorias discursivas.

Para tentar resolver essas questões apresentadas pelo sistemas de representação do conhecimento destacamos Antonio García Gutiérrez (2002) e sua epistemografia interativa. Esta tem como objetivo abordar a relevância das realidades diversas, analisando seu impacto no contexto de um pluralismo de culturas e de discursos, analisando, assim, os documentos tendo como comprometimento os saberes culturais. Michèle Hudon (1997) traz outra contribuição com a questão do multilinguismo para a construção de tesauros, já que as barreiras da língua podem interferir na representação dos documentos; seus estudos estão voltados para a construção de tesauros multilíngues que respeitem as línguas considerando a dimensão cultural e política no processo de construção. Por último Clare Beghtol (2002) analisa as questões da garantia e hospitalidade cultural. Os sistemas de organização e representação do conhecimento devem promover a garantia cultural, ou seja, serem adequados e úteis para os sujeitos em determinada cultura. Mas para isso precisam ser construídos tendo como base as suposições, valores e predisposições desta mesma cultura. A noção de hospitalidade cultural vem do conceito de hospitalidade já existente nos sistemas de classificações bibliográficas, mas a autora amplia o conceito para que o sistema acomode de forma ideal as diversas garantias das mais diversas culturas, seja ela de um indivíduo, grupo ou comunidade.
No âmbito brasileiro também temos pesquisadores que direcionam suas pesquisas para as questões éticas na organização e representação do conhecimento. Por exemplo, Miranda et al. (2012) oferece subsídios para a construção e reforma de sistemas de organização do conhecimento de maneira que estes contemplem, de forma satisfatória, a representação do conhecimento afrodescendente. Para atingir seu objetivo, o autor busca analisar a representação do conhecimento afrodescendente em sistemas de organização do conhecimento, estimulando a criação de um fórum permanente congregando os atores do processo de construção de sistemas de organização do conhecimento (afrodescendentes, profissionais da informação e classificacionistas), bem como identificar preconceitos e discriminações nos sistemas de organização do conhecimento.

Adensando os temas transversais, veremos $\mathrm{Pi}$ nho (2010) e Milani (2010) falando de, respectivamente, sexualidade e questões de gênero. Milani, por exemplo, aborda além das questões de gênero as categorizações dicotômicas tão presentes no pensamento ocidental e a falta de garantia e hospitalidade cultural, também presentes nos nossos universalismos. Apesar de Murguia não ter se dedicado às linguagens documentárias stricto sensu, sempre esteve voltado para os processos arquivísticos e patrimoniais geradores de documentos e materialidades.

\section{Conclusão}

Nos textos aqui reunidos sobre saber-poder envolvendo as áreas informacionais, nota-se a construção de uma compreensão, até certo ponto rara sobre a inadequação de critérios cientificistas e hegemônicos da Ciência da Informação em sua formação discursiva. Dizemos construção porque percebemos nosso autor titubear; sua crítica aos neodocumentalistas confirma a necessidade de considerarmos esta ciência uma ciência "Acho que hoje em dia, ninguém mais duvida que ela não seja uma ciência, ela é uma ciência em todos os sentidos. No caso do Brasil, ela alcançou um nível de teoria e reflexão admirável" (entrevista). Ao mesmo tempo que defende a ciência da informação como ciência fazendonos crer sobre a insuficiência do pressuposto humanista dos neodocumentalistas, Murguia também se apoia neles para entender o cientificismo da ciência da informação como um discurso de produção da verdade, como faz crer suas referencias a Ronald Day (2000) (Murguia, 20142015, p. 174; Murguia, 2010b p. 3). 
As recomendações de Murguia para que nos utilizemos mais de processos arqueológicos e genealógicos ao invés de puramente epistemológicos, na análise de nossa ciência, seja talvez o grande legado deste novo arquivista chegado à cidade.

A força de um pensamento arqueológico como o realizado por Murguia neste texto sobre a discursividade da Ciência da Informação talvez esteja na percepção de que as áreas não pertencem a um mesmo solo epistemológico (biblioteconomia, arquivística ou museologia são áreas milenares, ainda que a modernidade as reconfigura em práticas específicas em suas abrangências nacionais). A chegada, no entanto, dessas práticas à contemporaneidade causa efeitos de semeIhança em suas instituições correspondentes, como lugares de memória. O próprio Murguia considera a memória um lugar de diálogo entre arquivos, bibliotecas e museus (2010c). Mas os saberes desenvolvidos por essas áreas em seus processos de constituição aponta solos epistemológicos diferenciados, o que impediria de pronto a homogeinização e sujeição de seus saberes à uma ciência nascida no século XX (Murguia, 2014-2015, p. 177):

Observo a recente apropriação da documentação como elemento explicativo da formação da ciência da informação, em outras palavras como a sua origem. Esse fenômeno começa nos EUA, nas décadas de 1990 e 2000. Essa abordagem coloca um problema da filosofia da história que precisa ser evidenciado: a explicação do presente pelo passado

A grande inovação metodológia da arqueologia em relação à história das ideias ou à história das ciências é a noção de episteme. E para compreender a episteme é preciso partir da noção de saber, como alerta Machado (2007, p. 132-133) pois a arqueologia é uma história dos saberes. $\mathrm{E}$ os saberes tem uma positividade, uma presença. Murguia busca identificar essa presença em saberes biblioteconômicos ou arquivísticos quase que convocando uma nova geração de historiadores para responder se "realmente elas precisam ou não da cientificidade para continuar existindo" (Murguia, 2014-2015, p. 176).

Se a arqueologia é o método próprio à discursividade local, a genealogia é a tática que, a partir da discursividade local, ativa os saberes libertos, como esclarece Foucault (2016, p. 98):

[...] enquanto a arqueologia é o método próprio à análise da discursividade local, a genealogia é a tática que, a partir da discursividade local assim descrita, ativa os saberes libertos da sujeição que emergem desta discursividade.

\section{Referências}

Beghtol, C. (2002). Universal concepts, cultural warrant, and cultural hospitality. // López-Huertas, M. J (Ed.). Challenges in knowledge representation and organization for the 21 st century: integration of knowledge across boundaries. Wurzburg: ERGON-Verlag. 45-49.

Burke, P. (2003). Uma história social do conhecimento: de Gutenberg a Diderot. Rio de Janeiro: Jorge Zahar Editor.

Cook, T. (2012). Entrevista. // InCID: Revista de Ciência da Informação e Documentação. Ribeirão Preto, 3:2, jul/dez. http://www.revistas.usp.br/incid/article/view/48658/52729 (2015-12-01).

Day, Ronald (2000). Tropes, history, and ethics in professional discourse and Information. // Journal of the American Society for Information Science. 3:51 (2000) 469-475

Deleuze, G. (2006). Foucault. São Paulo: Brasiliense, 2006.

Foucault, M. (2010). Em defesa da sociedade: curso no Collège de France (1975-1976). São Paulo: Martins Fontes.

Foucault, M. (2013) A ordem do discurso: aula inaugural no Collège de France, pronunciada em 2 de dezembro de 1970. 23.ed. São Paulo: Edições Loyola.

Foucault, M. (2014). Microfísica do poder. Rio de Janeiro: Paz e Terra.

Foucault, M. (2015). A ordem do discurso. São Paulo: Folha de São Paulo.

Frohmann, B. (2009). Revisiting "what is a document?" // Journal of Documentation. 65:2. 291-303.

García Gutiérrez, A. (2002). A. La memoria subrogada: mediación, cultura y consciência en la red digital. // Granada: Editorial de la Universidade de Granada.

Grigoleto, M. C.; Murguia, E. I. (2013) O documento e seus agenciamentos institucionais: a construção do tombamento patrimonial da casa de Prudente de Moraes. // Agora. 23. 5-34.

Hudon, M. (1997). Multilingual thesaurus construction: integrating the views of diferente cultures in one gateway to knowlege and concepts. // Knowledge Organization, Wurzburg, 24:2, 84-91.

Machado, R. (2007). Foucault, a ciência e o saber. // Rio de Janeiro: Zahar

Mai, J. (2004). Classification in contexto: relativity reality, and representation. // Knowledge Organization, Wurzburg, $31: 1$, p. 39-48

Milani, S. O. (2010). Estudos éticos em representação do conhecimento: uma análise da questão feminina em linguagens documentais brasileiras. // 2010, 140 f. Dissertação (mestrado) - Universidade Estadual Paulista, Faculdade de Filosofia e Ciências.

Miranda, M. L. C.; Paranhos, J. P. B.; Oliveira, J. X.; Paes, M. S. A (2012). organização e representação do conhecimento em religiões yorubanas na Library of Congress Subject Headings. // Guimarães, J. A. C.; Dodebei, V. (Orgs.). Desafios e perspectivas científicas para a organização e representação do conhecimento na atualidade. Marília: ISKO-Brasil: FUNDEP, 2011. 153-159. http://isko-brasil.org.br/wp-content/uploads/2013/02/Livro-finalizado_correcoes-feitas_pronto-para-publicar07_02_2013.pdf (2015-12-01).

Mostafa, S. P. (2011). A documentalidade como conceito filosófico. // Crippa, G.; Mostafa, Solange P. Ciência da Informação e Documentação. Campinas: Átomo Alínea.

Murguia, E. I. (2009). O colecionismo bibliográfico: uma abordagem do livro para além da informação. // Encontros Bibli: Revista Eletrônica de Biblioteconomia e Ciência da Informação. número especial, 1 semestre, 87-104. 
Murguia, E. I. (2010) (Org.). Memória: um lugar de diálogo para Arquivos, Bibliotecas e Museus.// São Carlos: Compacta. $135 \mathrm{p}$.

Murguia, E. I. (2010a). Da Ciência da Informação à Cultura Material: os conceitos de Fundo e Coleção como princípios da organização. // Relatório de pesquisa. 2010. http://www.ibict.br/capacitacao-e-ensino/pesquisa-emciencia-da-informacao/pos-doutorado/pesquisas-concluidas-1/da-ciencia-da-informacao-a-cultura-material-osconceitos-de-fundo-e-colecao-como-principios-da-organizacao/Eduardo\%20Murguia_\%20Relatorio\%20PosDoutorado.pdf (2015-10-14)

Murguia, E. I. (2010b). Discursividade da Ciência da informação e sua insitucionalização na Biblioteconomia e na Arquivologia: um estudo comparado. // ENANCIB, XI. Rio de Janeiro, 25 a 28 de outubro de 2010. http://enancib.ibict.br/index.php/enancib/xienancib/paper/viewFile/ 3395/2521.

Murguia, E. I. (2011). Percepções e aproximações do documento na historiografia, documentação e ciência da informação. // InCID: Revista de Ciência da Informação e Documentação. 2:2, 42-53. http://www.revistas.usp.br/incid/article/view/42350/46021.

Murguia, E. I. (2013). As articulações políticas na criação do Instituto Brasileiro de Bibliografia e Documentação (IBBD). // Datagramazero. 14 (2013).

Murguia, E. I. (2014a). Entrevista. // InCID: Revista de Ciência da Informação e Documentação. 5:2, 164-184. http://www .revistas.usp.br/incid/article/view/84841/pdf_37 (201510-14).
Murguia, E. I. (2014b). Saber/poder: os agenciamentos da Ciência da Informação com a Biblioteconomia e a Arquivologia no Brasil. // InCID: Revista de Ciência da Informação e Documentação. 5:1, 4-26. http://www.revistas.usp.br/incid/article/view/64335/pdf_21 (2015-10-14).

Olson, H. A. (2002). The power to nome: locating the limits of subject representation in libraries. // Dordrechet: Kluwer Academic Publishers, 2002.

Pedrão, G. B.; Murguia, E. I. (2013). Formação de bibliotecas: uma abordagem desde a perspectiva do colecionismo. // Em Questão. 19 (2013) 2-17.

Pinho, F. A. (2010). Aspectos éticos em representação do conhecimento em temáticas relativas à homossexualidade masculina: uma análise da precisão em linguagens de indexação brasileiras. // 2010. 149 f. Tese (doutorado). Universidade Estadual Paulista, Faculdade de Filosofia e Ciências.

Rafferty, P. (2001). The representation of knowledge in library classification schemes. // Knowledge Organization, Wurzburg, 28:4, p. 180-191.

Rayward, W. B. (1996). The history and historiography of information science: some reflections. // Information Processing \& Management. 32:1, 3-17. http://web.simmons.edu/ watkins/rayward.pdf. (2015-10-14).

Enviado: 2016-03-23 Aceptado: 2015-04-12. 